\title{
Female hyperandrogenism and elite sport
}

\author{
Angelica Lindén Hirschberg ${ }^{1,2}$ \\ ${ }^{1}$ Division of Obstetrics and Gynaecology, Department of Women's and Children's Health, Karolinska Institutet, Stockholm, Sweden \\ ${ }^{2}$ Department of Gynecology and Reproductive Medicine, Karolinska University Hospital, Stockholm, Sweden.
}

Correspondence should be addressed to A L Hirschberg: angelica.linden-hirschberg@sll.se

\begin{abstract}
Emerging evidence indicates that testosterone, which can increase muscle mass and strength, stimulates erythropoiesis, promotes competitive behaviour, and enhances the physical performance of women. Indeed, the levels of testosterone within the normal female range are related to muscle mass and athletic performance in female athletes. Furthermore, among these athletes, the prevalence of hyperandrogenic conditions, including both polycystic ovary syndrome and rare differences/disorders of sex development (DSD), which may greatly increase testosterone production, are elevated. Thus, if the androgen receptors of an individual with XY DSD are functional, her muscle mass will develop like that of a man. These findings have led to the proposal that essential hyperandrogenism is beneficial for athletic performance and plays a role in the choice by women to compete in athletic activities. Moreover, a recent randomized controlled trial demonstrated a significant increase in the lean mass and aerobic performance by young exercising women when their testosterone levels were enhanced moderately. Circulating testosterone is considered the strongest factor to explain the male advantage in sport performance, ranging between 10 and 20\%. It appears to be unfair to allow female athletes with endogenous testosterone levels in the male range (i.e. 10-20 times higher than normal) to compete against those with normal female androgen levels. In 2012, this consideration led international organizations to establish eligibility regulations for the female classification in order to ensure fair and meaningful competition, but the regulations are controversial and have been challenged in court.
\end{abstract}

\section{Key Words}

- female athletes

- hyperandrogenism

- polycystic ovary syndrome

- disorders of sex development

- physical performance

\section{Introduction}

The proportion of women who engage in sports at all levels has increased dramatically over the past 50 years, as reflected in the rising proportion of female Olympic competitors. For example, at the summer Olympics in Munich in 1972, 15\% of the participants were women, in comparison to $44 \%$ in 2012, in London, the first Olympics in which women competed in all disciplines. In fact, the proportion of female participants in the Olympic Games is now approaching 50\%, which can hopefully encourage even more women to engage in sports.

However, at the same time, elite sportswomen appear to be at greater risk for certain injuries than male athletes, such as stress fractures and knee injuries, which could shorten the women's sports careers. Furthermore, endocrine disturbances are common among female athletes, as shown by an increased prevalence of menstrual disorders like amenorrhea. Such disturbances could either be a consequence of intense physical exercise or result from overrepresentation of women with these types of endocrine characteristics in elite sports. Essential hyperandrogenism is one example of the latter that has received much attention in recent years.

The present overview describes our current state of knowledge about elite female athletes concerning the following areas:

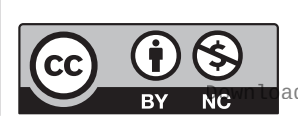

This work is licensed under a Creative Commons Attribution-NonCommercial 4.0 International License. ded from Bioscientifica.com at 04/26/2023 12:13:17PM 
a) Mechanisms underlying menstrual disorders

b) Mild and severe forms of hyperandrogenism

c) Sex differences in athletic performance

d) The impact of androgens on physical performance

e) Regulations concerning the eligibility to compete in the female classification

\section{Menstrual disorders among female athletes}

\section{Functional hypothalamic amenorrhea}

Amenorrhea is common among athletes, particularly those participating in sports where a lean body is considered advantageous to physical performance, such as esthetic and endurance sports (1). First described in the late 1970s, this medical condition became known as 'athletic amenorrhea', that is, loss of menstruation as a result of intense physical training (2).

Athletic amenorrhea is considered a functional disturbance attributed to inhibition of the hypothalamicpituitary-gonadal (HPG) axis, and named functional hypothalamic amenorrhea (FHA), which disrupts the pulsatile release of gonadotropin-releasing hormone (GnRH) from the hypothalamus. This, in turn, reduces pituitary secretion of luteinizing hormone (LH) and follicle-stimulating hormone (FSH), resulting in attenuated ovarian production of sex steroids, including estradiol, progesterone and testosterone, as well as subsequent anovulation and amenorrhea (3).

Several mechanisms underlie such inhibition of the HPG axis (Fig. 1), including exercise-induced activation of the hypothalamic-pituitary-adrenal axis and a consequent increase in hypothalamic secretion of corticotropinreleasing hormone and of cortisol from the adrenal glands $(3,4)$. These stress hormones together with the endorphins, also released in response to physical activity, inhibit GnRH secretion by the hypothalamus $(3,4,5,6)$.

Furthermore, athletic amenorrhea is associated with a hypometabolic state, as reflected in low circulating levels of insulin and insulin-like growth factor I (IGF-I) and high levels of growth hormone and IGF-binding protein-1 (Fig. 1) $(4,7,8)$. Because IGF-I stimulates the release of both GnRH and LH, a decline in IGF-I activity may, at least in part, explain the reduction in LH secretion. In addition, serum levels of leptin, a marker of nutritional status also involved in the pulsatile secretion of $\mathrm{GnRH}$, are markedly reduced in amenorrheic athletes (9), as are levels of thyroxin and triiodothyronine (10).

Altogether, these findings indicate that athletic amenorrhea is due to central inhibition of the reproductive

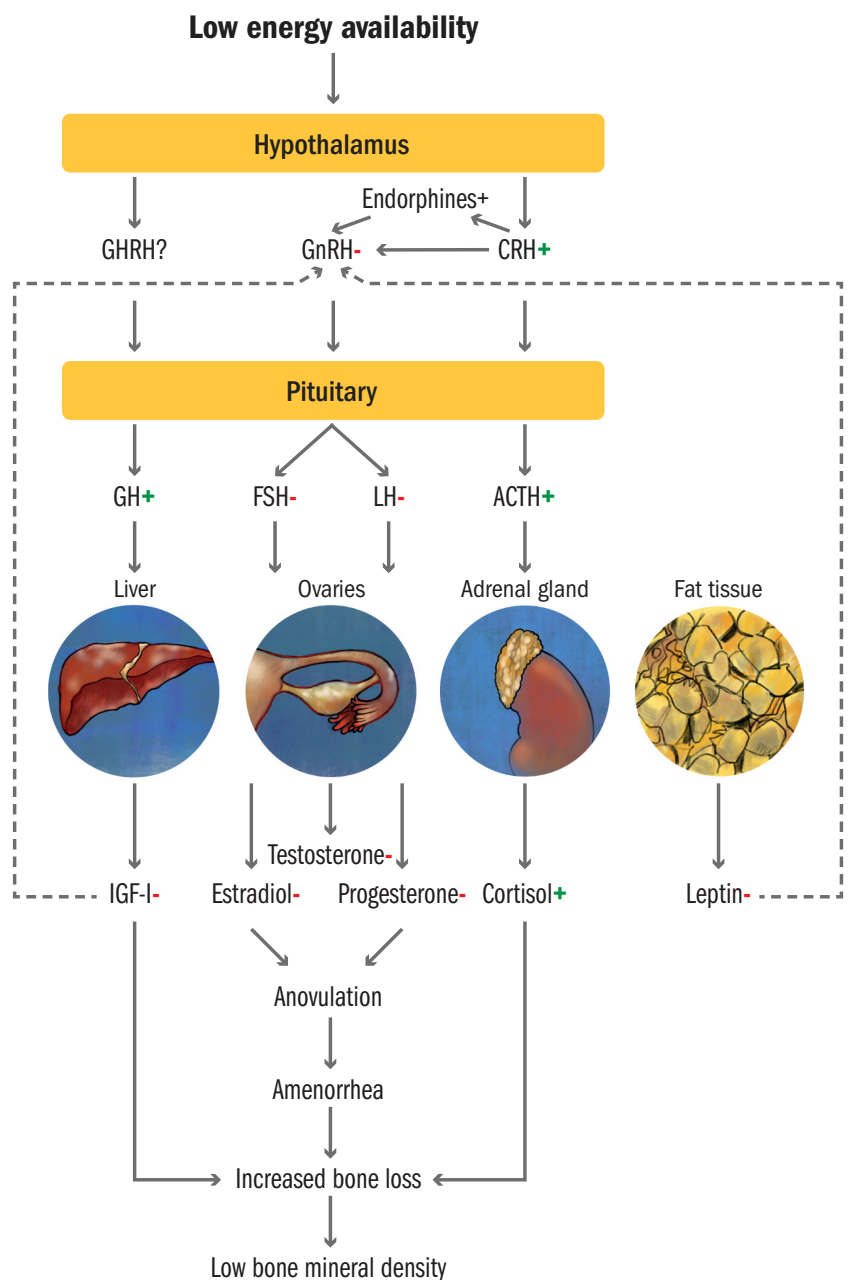

Figure 1

A summary of endocrine disturbances associated with athletic amenorrhea. For explanations and abbreviations, see the accompanying text. Reprinted from Encyclopedia of Endocrine Diseases; 2nd edn, vol 2; Eds I Huhtaniemi \& L Martini; Sport and menses; pp 461-470; copyright 2019; with permission from Elsevier (4).

axis by stress hormones and endorphins, in combination with attenuated stimulation of $\mathrm{GnRH}$, as a consequence of low levels of IGF-I and leptin.

Today, the most important underlying cause of athletic amenorrhea is understood to be an energy intake that is substantially less than energy expenditure (11, $12,13)$, sometimes due to the desire to be lean (14). A relatively low amount of body fat in relation to muscle mass is important for performance in many disciplines, including endurance, weight-class and esthetic sports. At the same time, strict control of food intake can develop into eating disorders, which are more prevalent among athletes than in the general population (15).

Low energy availability, amenorrhea and estrogen deficiency are associated with rapid loss of bone mass and

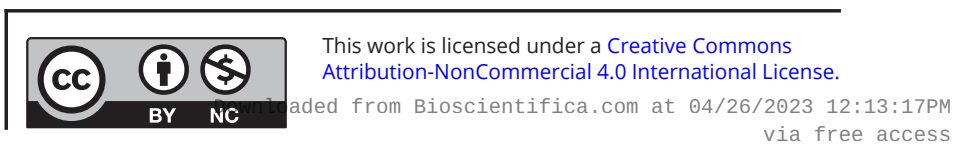


an elevated risk for musculoskeletal injuries (Fig. 1). Since physical activity usually promotes bone formation, it was initially considered paradoxical that elite athletes could exhibit reduced bone mass $(16,17)$. This phenomenon is now known to arise from nutritional deficiency and its endocrine consequences, including low levels of estradiol, testosterone and IGF-I and enhanced levels of cortisol (18).

FHA is an acquired condition that can be reversed by restoring the balance between energy intake and expenditure, and this should be the initial intervention for athletes with this condition (19). If nutritional counseling and adjustment of training for at least 1 year does not lead to resumption of menses, estrogen substitution can be considered (20).

\section{Hyperandrogenism among female athletes}

Although insufficient energy availability and the resulting FHA are probably the most common cause of amenorrhea among exercising women, not all sportswomen with menstrual disorders are hypometabolic. In fact, we have identified polycystic ovary syndrome (PCOS) as an alternative explanation $(21,22,23)$.

\section{Polycystic ovary syndrome}

PCOS is probably the most frequent endocrine disorder among women of fertile age, affecting approximately $10 \%$ of the female population (24). This syndrome is characterized by elevated ovarian production of androgens, disturbed ovulation and ultrasound findings of polycystic ovaries. Although the aetiology of PCOS remains largely unknown, there are strong indications of a genetic predisposition.

Hyperandrogenism and insulin resistance, the characteristic endocrine features of the pathogenesis of PCOS, explain the various associated symptoms (24). The primary abnormality appears to be increased production of androgens by the ovaries, augmented by disrupted feedback control of pulsatile GnRH secretion, resulting in elevated secretion of $\mathrm{LH}$ and relative FSH deficiency. The clinical consequences are the characteristic polycystic ovarian morphology and anovulation leading to menstrual disorders and reduced fertility, as well as hirsutism and acne. In addition, women with PCOS are more insulin resistant, independent of obesity, leading to secondary hypersecretion of insulin, which directly stimulates androgen production by the ovarian theca cells.
Furthermore, insulin inhibits hepatic synthesis of sex hormone-binding globulin (SHBG), thereby elevating levels of free and bioavailable testosterone. Moreover, insulin resistance may lead to metabolic changes including abdominal obesity.

This condition is usually managed by treating the symptoms, including menstrual disorders, infertility, hirsutism and overweight/obesity (24), although specific treatment is not always being necessary. However, a healthy lifestyle, including regular physical activity, is clearly beneficial and should therefore be recommended first (25). Long-standing anovulation is thought to increase the risk of endometrial cancer, but oral contraceptives or cyclic progestogens can be used to regulate menstruation and abolish this risk. Furthermore, combined oral contraceptives attenuate androgenic effects and counteract hirsutism and acne. Physical activity usually improves the fertility of women with PCOS, but stimulation of ovulation or in vitro fertilization can otherwise be offered.

PCOS appears to be a common disorder among elite female athletes $(21,22,23,26,27,28,29)$ and is, indeed, the most frequent cause of menstrual disorders among Olympic sportswomen (23). We have demonstrated elevated diurnal secretion of LH and testosterone by athletes with PCOS than by those without (Fig. 2) (22). In contrast, in athletes with FHA due to energy deficiency, LH pulsatility is abolished and levels of testosterone are low (Fig. 2) (22). Thus, the hormonal profile associated with PCOS differs completely from that of FHA. At the same time, the level of testosterone in women with PCOS remains typically within the upper part of the normal range. The bodies of such athletes are more anabolic, with a greater amount of muscle mass and higher bone mineral density than other athletes (21). Furthermore, hyperandrogenism appears to protect effectively against bone loss, despite the oligomenorrhea/amenorrhea and relative estrogen deficiency (21).

In some athletes with amenorrhea, it can be a mixed underlying cause with both functional hypothalamic disturbance due to energy deficiency and PCOS.

\section{Differences/disorders of sex development}

A few women are born with rare conditions, referred to as differences/disorders of sex development (DSD), in which the development of chromosomal, gonadal and anatomic sex is atypical. These conditions are usually diagnosed at birth or during early childhood on the basis of ambiguous genitalia or else at the onset of puberty in girls due to

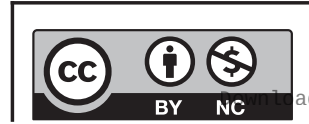

This work is licensed under a Creative Commons Attribution-NonCommercial 4.0 International License. ded from Bioscientifica.com at 04/26/2023 12:13:17PM 

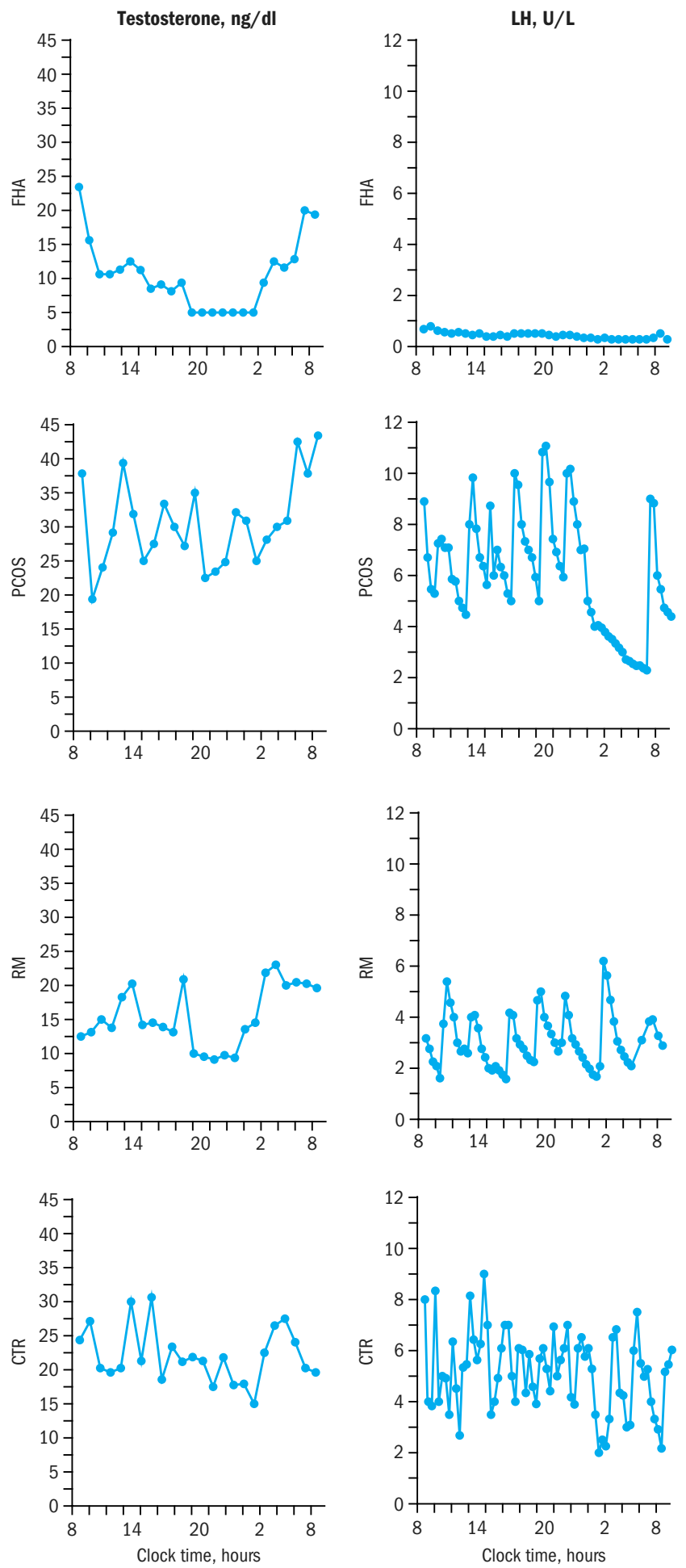

Figure 2

Typical diurnal hormonal profiles in individual female athletes and a sedentary control woman. $\mathrm{FHA}=$ athlete with functional hypothalamic amenorrhea; $\mathrm{PCOS}=$ athlete with polycystic ovary syndrome; RM = athlete with regular menstruation; CTR = sedentary control. Reprinted from Encyclopedia of Endocrine Diseases; 2nd edn, vol 2; Eds I Huhtaniemi \& L Martini; Sport and menses; pp 461-470; copyright 2019; with permission from Elsevier (4).

primary amenorrhea. However, in regions with limited medical resources and/or competence, such individuals may enter adulthood undiagnosed.

DSD involving a male karyotype and undescended, but functioning testes may greatly increase production of testosterone leading to levels similar to those in men (Table 1). If the androgen receptors of such an individual are functional, her muscle mass will develop as in men, along with other signs of virilization, including more body hair (hirsutism), deepening of the voice, atrophy of the breasts and an enlarged clitoris. Individuals with DSD have a varying risk of developing germ cell cancer (GCC). The characteristic features of 46,XY DSD conditions, described in detail elsewhere $(30,32,31)$, are presented briefly.

Deficiency of the enzyme $5 \alpha$-reductase type 2 , a very rare autosomal recessive condition caused by mutation in the SRD5A2 gene, results in failure to convert testosterone into dihydrotestosterone (DHT) (Table 1). Since the external development of male genitalia during fetal life is dependent on DHT, this condition will lead to varying degrees of undervirilization, despite the presence of testes and normal male production of testosterone, resulting in identification as a female at birth. However, during puberty, when circulating levels of testosterone rise to normal adult male levels, the individuals will undergo virilization and more than half will change their gender identity and become men. The risk of GCC with this condition is considered low.

Androgen insensitivity syndrome (AIS), caused by a mutation in the androgen receptor gene on the $\mathrm{X}$ chromosome, leads to various degrees of undervirilization in individuals carrying one $\mathrm{X}$ and one $\mathrm{Y}$ chromosome (Table 1). In the case of complete androgen insensitivity (CAIS), even though they have testes (undescended) and circulating levels of testosterone in the normal range for men, such individuals respond very little or not at all to androgens and will therefore appear to be fully female. However, with partial androgen insensitivity (PAIS), the phenotype will vary from that of a virilized woman to an undervirilized man. If the gonads are intra-abdominal, PAIS is associated with a clearly heightened risk of GCC in as much as $30-40 \%$. Gonadectomy is therefore recommended in this case.

A mutation in the $17 \beta$-hydroxysteroid dehydrogenase type 3 (17 $\beta$-HSD3) gene results in deficient conversion of androstenedione to testosterone (Table 1). Clinically, these XY individuals will develop undervirilized external genitalia and varying phenotypes, with some being identified as female at birth. However, as in the

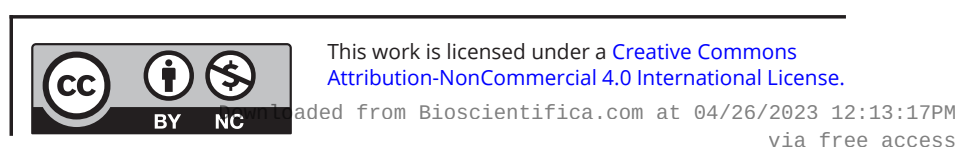


Table 1 Examples of 46,XY differences/disorders of sex development (DSD).

\begin{tabular}{|c|c|}
\hline Condition & Incidence \\
\hline $5 \alpha$-reductase deficiency type 2 & $\begin{array}{l}\text { Extremely rare with } \\
\text { geographical regions of } \\
\text { higher incidence }\end{array}$ \\
\hline Partial androgen insensitivity (PAIS) & $1 / 130,000$ \\
\hline $\begin{array}{l}\text { 17 } \beta \text {-hydroxysteroid dehydrogenase } \\
\text { type } 3(17 \beta \text { - HSD3) deficiency }\end{array}$ & $1 / 147,000$ \\
\hline Ovotesticular DSD & $1 / 100,000$ \\
\hline
\end{tabular}

\begin{tabular}{l} 
Comment \\
\hline $\begin{array}{l}\text { Individuals may be assigned female sex at } \\
\text { birth. Virilization proceeds at puberty. }\end{array}$ \\
Ambiguous genitalia at birth. From puberty, \\
high testosterone, but with varying effect \\
depending on androgen receptor sensitivity. \\
Individuals are often raised as girls but \\
undergo virilization at puberty. \\
The individual has both ovarian and testicular \\
tissue. Born with ambiguous genitalia. \\
Virilization may proceed at puberty.
\end{tabular}

\begin{tabular}{l}
$\begin{array}{l}\text { Advantage in } \\
\text { sports? }\end{array}$ \\
\hline Yes \\
Possibly \\
Yes \\
Possibly
\end{tabular}

case of $5 \alpha$-reductase deficiency, when the testes start to produce large amounts of androgens during puberty, such individuals undergo marked virilization and approximately half will change their gender identity to male. This condition is associated with a medium high risk of GCC.

Individuals with ovotesticular DSD (true hermaphroditism), another very rare condition with varying karyotype (although $46, \mathrm{XX}$ is most common), develop both ovarian and testicular tissue (Table 1). They can have an ovary on one side and a testis on the other or combined tissue, so called ovotestis. Depending on their gonadal tissue, their clinical phenotype varies widely, from that of a normal man to normal woman, although the nature of the external genitalia is often ambiguous. They can be considered to be either male or female and little is known about their gender identity. The risk of GCC is low in ovotesticular DSD.

The incidence of $46, \mathrm{XY}$ DSD in the general population is estimated to be 1 in 20,000 births (31). In comparison, the prevalence of this condition among female athletes participating in the World Championships was 7 in 1000, that is, 140 -fold higher (32). Since both mild and severe forms of hyperandrogenism appear to be particularly common among female athletes, it has been suggested that such conditions could enhance athletic performance and thus play a role in the decision by women to participate in competitive sports.

\section{Sex differences in athletic performance and levels of testosterone}

Biological sex is one of the most decisive determinants of athletic performance. In sports that rely on strength, men have, in general, a 10-20\% advantage over women, with the most pronounced difference in sports that involve primarily upper-body muscle strength (Table 2). This obvious sex difference, which remains even, although the performance of women has improved considerably over time, has led to the conclusion that competition between women and men would not be fair and meaningful and, consequently, most sports involve female and male competitions.

The average differences in physical characteristics that could confer such a male advantage include greater height (which is beneficial in certain sports), a more anabolic body composition (relatively more muscle mass than body fat) and greater muscle strength (30). Furthermore, the average sex differences in hemoglobin levels and behavioral patterns, including competitiveness, might give men an advantage over women $(30,33)$.

\section{Sex differences in circulating levels of testosterone}

Among all the variables that could play a role, the explanation for the sex difference in athletic performance that is most generally accepted involves circulating levels of testosterone, which are, on average, 10-20 times higher in men than women (30). Available measurements based on liquid chromatography-tandem mass spectrometry indicate that the normal female range is $0.1-1.8 \mathrm{nmol} / \mathrm{L}$ and the normal male range is $7.7-29.4 \mathrm{nmol} / \mathrm{L}$ (95\% two-sided confidence intervals (CI)) (Fig. 3).

Table 2 Sex differences in physical performance of Olympic gold medalists at the 2016 Olympics in Rio de Janeiro.

\begin{tabular}{l} 
Sport category \\
\hline $100-m$ running, $s$ \\
$5000-m$ running, min \\
High jump, m \\
Pole vault, m \\
Javelin, m \\
CC
\end{tabular}

\begin{tabular}{ccccc}
\hline Women & & Men & & Sex difference \% \\
\cline { 1 - 1 } 10.71 & & 9.81 & & 8.4 \\
$14: 26.17$ & & $13: 03.30$ & & 9.6 \\
1.97 & & 2.38 & & 17.2 \\
4.85 & & 6.03 & & 19.6 \\
66.18 & 90.30 & & 26.7 \\
\hline
\end{tabular}

This work is licensed under a Creative Commons Attribution-NonCommercial 4.0 International License. Aed from Bioscientifica com at 04/26/2023 12:13:17PM 


\section{Sex difference in circulating levels of testosterone}

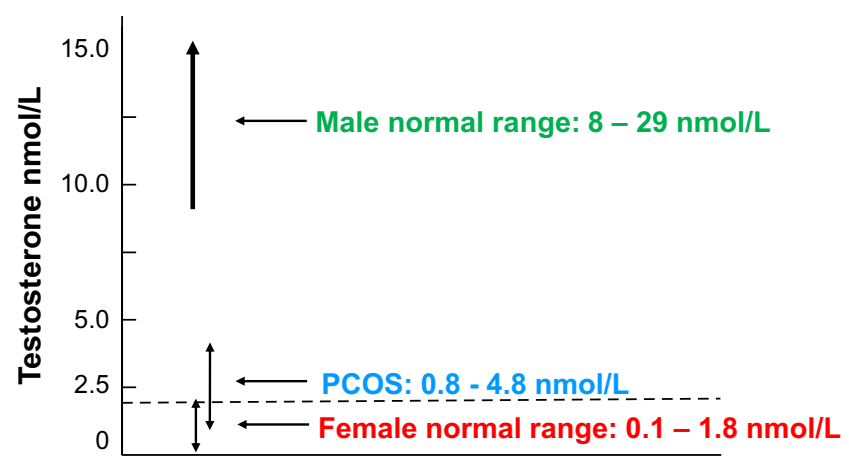

\section{Figure 3}

Illustration of sex difference in circulating testosterone levels. PCOS = polycystic ovary syndrome.

Even when women with mild hyperandrogenism, such as PCOS, are included, the upper female limit is $3.1 \mathrm{nmol} / \mathrm{L}$ (95\% one-sided CI) or $4.8 \mathrm{nmol} / \mathrm{L}$ (99.99\% CI) (Fig. 3) (30).

\section{Androgen secretion in women of fertile age}

In women of fertile age, about $50 \%$ of circulating testosterone is secreted directly in equal amounts by the ovaries and adrenal glands (34) (Fig. 4). The remaining $50 \%$ is produced by peripheral conversion of androgen precursors derived from the ovaries and adrenals. Androstenedione produced by the ovary, a precursor for both estrogens and androgens, can be converted to testosterone, which is transformed further into the even more potent DHT by the enzyme $5 \alpha$-reductase

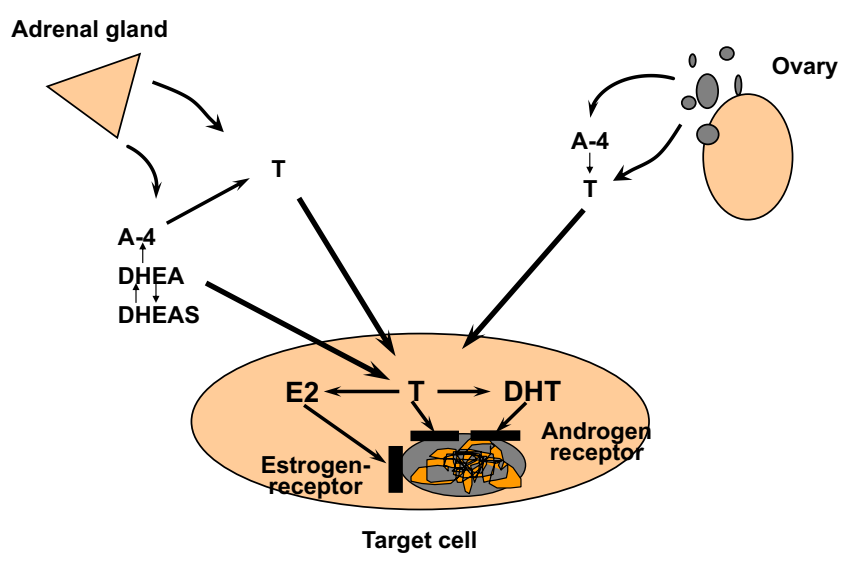

Figure 4

Androgen secretion in women. For explanation see the text. A-4 = androstendione; DHEA = dehydroepiandrosterone; DHEAS = dehydroepiandrosterone sulphate; $\mathrm{DHT}$ = dihydrotestosterone; E2 = estradiol; $T$ = testosterone. Adapted from (34), with permission of Springer Nature. located in the ovary itself and a number of peripheral tissues (liver, kidney, muscle, fat and skin) $(35,36)$. The adrenal gland produces dehydroepiandrosterone (DHEA), dehydroepiandrosterone sulphate (DHEAS), androstenedione, testosterone and small amounts of DHT. In peripheral tissues that express steroidogenic enzymes, the precursors DHEA and DHEAS can be converted into estradiol, testosterone and DHT $(35,36)$. Indeed, in women, DHEA is considered a major tissue-specific source of testosterone and DHT (37).

Approximately $65-70 \%$ of circulating testosterone is bound to SHBG, a protein secreted by the liver, with $30-35 \%$ of testosterone being bound loosely to albumin and only $0.5-3 \%$ free (38). The free and albumin-bound fractions are considered to be bioavailable testosterone. However, the free androgen index, that is, the ratio of total testosterone to SHBG multiplied by 100 , is used as a measure of circulating free testosterone. DHT in the circulation is bound even more strongly to SHBG than testosterone. Liquid (or gas) chromatography-mass spectrometry is considered as the golden standard for analysis of serum testosterone, since immunological methods are limited by cross-reactivity with other steroids and insufficient sensitivity.

\section{Potential enhancement of physical performance by androgens}

Testosterone and DHT are the two androgens that clearly bind to the androgen receptor and thereby exert anabolic activity (Fig. 4). Although recent evidence indicates that 11-ketotestosterone and 11-ketodihydrotestosterone, androgen derivates produced by the adrenal gland, are also potent agonists of the human androgen receptor (39), their potential biological role requires further elucidation.

Androgens could enhance athletic performance through their effects on muscle tissue, bone mass, erythropoietin, the immune system and behavioral patterns $(30,33,40,41)$, although most studies in this context to date have been performed on men. In muscle tissue, androgens increase the number of muscle fibers, satellite cells and myonuclei, as well as the size of motor neurons (42). Moreover, experimental findings indicate that testosterone elevates the expression of skeletal muscle myostatin, mitochondrial biogenesis, myoglobin expression and the muscular content of IGF (43), all of which may enhance skeletal muscular activity. Obviously, muscle growth and the accompanying increase in strength and power could enhance performance.

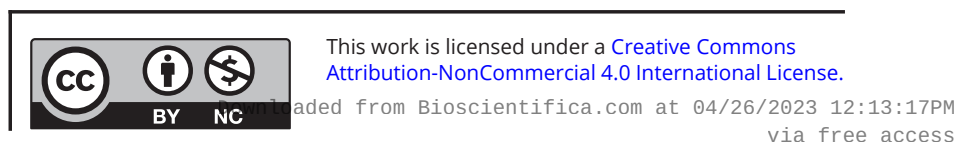


In addition, bone formation is stimulated by androgens, both directly and in part following their local aromatization to estrogens (44). In experimental animals, androgens stimulate the proliferation and differentiation of osteoblasts and inhibit apoptosis of these cells through specific receptor mechanisms (41). Furthermore, the androgen-stimulated increase in muscle mass and strength promotes bone formation (41). Stimulation of bone size and strength could be beneficial in connection with sports involving activities such as jumping, throwing and other explosive movements.

Furthermore, testosterone stimulates the formation of new erythrocytes and elevates circulating levels of hemoglobin (45), apparently as a result of secretion of more erythropoietin and less hepcidin (46). Experiments performed in the 1970s revealed a close linear relationship between hemoglobin levels and maximal oxygen consumption during exercise (47).

Androgens may also exert behavioral and psychological effects that influence athletic performance. Administration of exogenous testosterone to men enhances their competitive and dominant behavior and reduces fear $(48,49)$, as well as promotes high-risk behavior $(49,50)$. Furthermore, androgens may affect cognition and mood. Although some evidence indicates that testosterone improves spatial ability in both women and men, these findings are not yet definitive $(51,52)$. Clearly, spatial ability is important in many sports, such as pole vault and hammer throw.

\section{Exogenous androgens and physical performance in women}

Ever since the 1950s, administration of exogenous androgens has been used to enhance athletic performance, with reports of consequent increases in power, strength and training capacity (49). These substances, now labeled as doping agents, are banned from sports. Besides the few research investigations regarding the effects of exogenous anabolic androgens on female athletes are the unethical experiments performed in the former German Democratic Republic (GDR), where disclosed documents reveal that athletes were administered such substances from an early age (53). The positive effects of androgens on athletic performance were found to be even more pronounced for women than men. After the GDR ceased to exist in 1989 , the performance of the world's best female athletes in several sports declined markedly.
The sparsity of research investigations on the effects of exogenous testosterone on the physical performance of women probably reflects the ethical concerns about potential adverse effects. In one study on postmenopausal women, administration of different doses of testosterone (reaching a maximal mean circulating level of $7.3 \mathrm{nmol} / \mathrm{L}$ ) for 24 weeks resulted in dose-dependent increases in mean muscle mass by as much as $4.4 \%$ and in muscle strength by $12-26 \%(54)$.

Recently in our double-blind, randomized, placebocontrolled study (RCT), 48 healthy, physically active women, 18-35 years of age, were allocated randomly to 10 weeks of daily treatment with $10 \mathrm{mg}$ testosterone cream or placebo cream (55). In those receiving the testosterone cream, serum levels of testosterone rose from a mean of $0.9 \pm 0.4$ to $4.3 \pm 2.8 \mathrm{nmol} / \mathrm{L}$ and their aerobic performance (running time to exhaustion) improved by $8.5 \%$, which was significantly more than for the placebo group (Fig. 5). At the same time, the anaerobic performance (assessed by the Wingate test) of the women receiving testosterone improved by $3.2 \%$, but this was not significantly different than placebo (Fig. 5). Although muscle strength was unaltered, testosterone enhanced lean body mass (2.0\%) significantly without changing body weight. Altogether, these findings demonstrate that exogenous testosterone elevates the muscle mass and improves the physical performance of young, physically active women.

\section{The influence of endogenous androgens on the physical performance of women}

The influence on the athletic performance of women of endogenous androgen levels that are within the normal range has rarely been studied, whereas in men there is evidence for an association between normal levels of endogenous testosterone and physical performance in both athletes and non-athletes $(30,56,57)$. One reason for the lack of such investigation on women could be the complications introduced by hormonal variations during the menstrual cycle and usage of hormonal contraception.

One earlier report including female athletes $(n=22)$ demonstrated that serum levels of testosterone at rest were positively correlated with explosive performance (the vertical jump test) (57). A much larger study involved more than a 1000 elite female participants in the 2011 and 2013 International Association of Athletics Federations (IAAF) World Championships $(58,59)$, of whom only $1.8 \%$ had

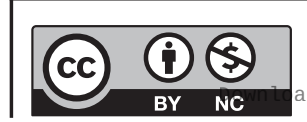

This work is licensed under a Creative Commons Attribution-NonCommercial 4.0 International License. ded from Bioscientifica.com at 04/26/2023 12:13:17PM 

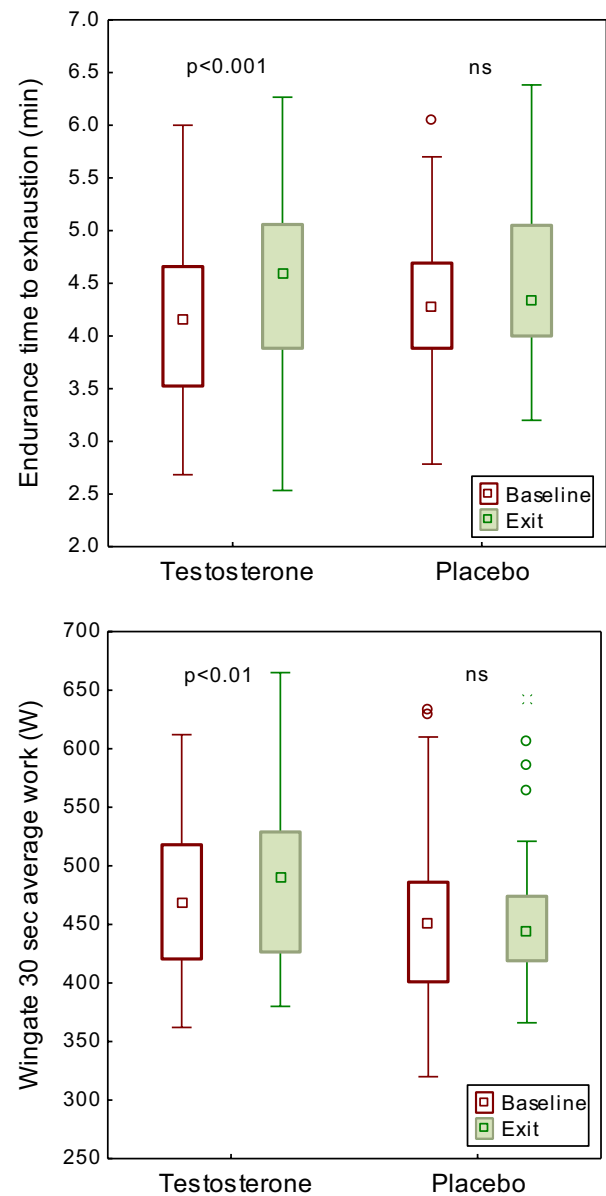

\section{Figure 5}

Aerobic performance measured as endurance time to exhaustion and anaerobic performance measured as Wingate 30-s average work, before and after 10 weeks of treatment with testosterone or placebo in young, physically active, healthy women. $n=24$ in each group. Values are median and total range. Endurance time to exhaustion increased significantly in the testosterone group compared with the placebo group, whereas the change in Wingate power was not significantly different between the groups. Data from (55).

clearly elevated levels of testosterone indicative of DSD or doping. These athletes were classified in tertiles on the basis of their levels of testosterone, and the performance in those in the highest tertile in the 400-m race, 400-m hurdles and $800-\mathrm{m}$ race was found to be $2.1-2.5 \%$ better than that of those in the lowest tertile. Combined performance in events from 400 to $1500 \mathrm{~m}$ in length was significantly correlated to the testosterone level.

In another study, we examined more than 100 female Swedish Olympic athletes and sedentary controls of the same age and BMI with respect to muscle and bone mass, muscular strength and androgen profile in both the serum and urine (60). Although the athletes exhibited serum androgen levels within the normal range, their level of androgen precursors, including DHEA, were higher and estrone levels lower than those of the controls. Furthermore, the athletes had higher bone mineral density and more lean mass. In addition, serum levels of DHT and DHEA correlated positively with the physical performance of the athletes. This observation is important since accumulating evidence indicates that, in women, DHEA is the major precursor of bioactive androgens, being converted intracellularly into testosterone and DHT, which bind to the androgen receptor (37).

Together, these findings indicate that, in female athletes, even normal levels of endogenous androgens are positively correlated to lean mass and physical performance.

\section{Hyperandrogenism and the performance of female athletes}

\section{Polycystic ovary syndrome}

Although information concerning the influence of hyperandrogenism on physical performance by women is limited, some evidence indicates that PCOS is beneficial in this context. For instance, endurance athletes with PCOS perform significantly better in the Beep test and exhibit higher maximal oxygen uptake $\left(\mathrm{VO}_{2}\right.$ max) during the treadmill exhaustion test than other female athletes with the same BMI (Fig. 6) (21). Androgen levels were positively correlated to $\mathrm{VO}_{2}$ max and lean mass in the same study.

In another case-control study involving 40 sedentary women with PCOS and 40 controls, those with PCOS showed greater muscle strength (bench press,

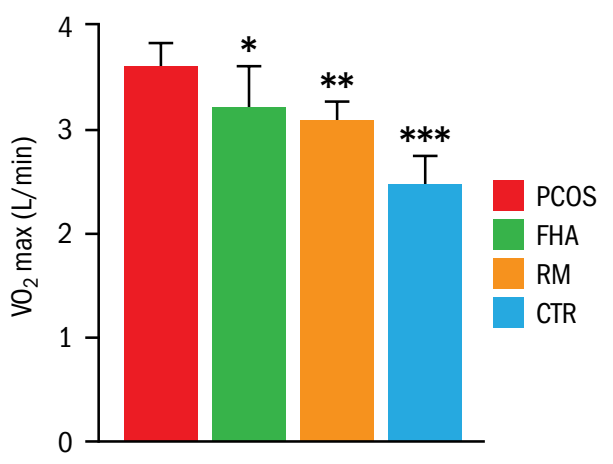

Figure 6

Maximal oxygen uptake in groups of athletes with polycystic ovary syndrome (PCOS), functional hypothalamic amenorrhea (FHA) and regular menstruation (RM) and in a sedentary control group (CTR). Reprinted from Encyclopedia of Endocrine Diseases; 2nd edn, vol 2; Eds I Huhtaniemi \& L Martini; Sport and menses; pp 461-470; copyright 2019; with permission from Elsevier (4).

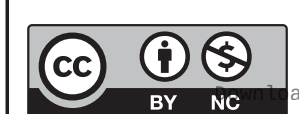

This work is licensed under a Creative Commons Attribution-NonCommercial 4.0 International License. ded from Bioscientifica.com at 04/26/2023 12:13:17PM via free access 
leg extension and handgrip strength), irrespective of body composition (61). Serum levels of testosterone correlated positively with increased muscle strength in the PCOS group (61). Furthermore, polycystic ovaries and PCOS are overrepresented among Olympic sportswomen, as well as other athletic populations $(23,26,27,28$, 29). These observations indicate that mild forms of hyperandrogenism such as PCOS may improve physical performance and thereby play a role in the decision by women to participate in competitive sports. There is no support for the reverse causality, that is, participation in sports elevates the incidence of polycystic ovaries or PCOS.

\section{Differences/disorders of sex development}

The increased prevalence of XY DSD among elite female athletes suggests that these conditions may improve physical performance. However, for obvious reasons, the physical performance of groups of female athletes with such rare conditions has yet to be compared to that of controls and only a few individual case studies have been reported. According to these reports, treatment designed to lower testosterone levels also worsened performance on the average by $5.7 \%$ over a 2-year period (62).

At the cell level, the body cannot distinguish between exogenous or endogenous testosterone, and therefore the physiological/biological effect of testosterone could be studied by administrating testosterone to subjects. In our RCT concerning the influence of testosterone on the physical performance of young, physically active women (55), we found a significant increase in lean body mass (2\%), aerobic performance $(8.5 \%)$ and anaerobic performance (3.2\%, not statistically significant in comparison to placebo) when serum levels of testosterone were increased modestly (to approximately half the lower limit of the normal male range), by exogenous administration (Fig. 5). Since the dose-response relationship between testosterone and physical performance in young women is not known, the results cannot be extrapolated directly to indicate the effects of male levels of testosterone. However, on the basis of available data, it has been estimated that the ergogenic advantage to a female athlete provided by circulating levels of testosterone in the male range is greater than $9 \%$ (30).

\section{Regulations concerning the eligibility to compete as a woman in sports}

To ensure fair and meaningful competition, the IAAF, now Word Athletics, introduced in 2011, for the first time, regulations concerning the eligibility of female athletes with hyperandrogenism to compete with other women. These rules were endorsed by the International Olympic Committee (IOC) prior to the Olympic Games in London 2012. According to these regulations, an athlete can compete in the female category if she is legally recognized as a woman and has testosterone levels below $10 \mathrm{nmol} / \mathrm{L}$. However, an exception is CAIS, since in this case the individual cannot respond to testosterone although she has testosterone in the male range. These rules, designed to preserve the safety, fairness and integrity of women's competition, and in no way to determine sex or gender, have been subjected to debate and criticism $(63,64,65$, $66,67,68)$.

In 2015, the regulations were challenged by an athlete in the Court of Arbitration of Sport (CAS), which then suspended them pending further scientific evidence concerning the influence of testosterone levels in the male range on the athletic performance of women. In response, recent observational data $(58,59,60)$, as well as our RCT described, (55) have provided additional evidence for the performance-enhancing effects of testosterone in female athletes.

Later on, the IAAF issued new regulations for the female classification - Athletes with Differences of Sex Development - which finally came into effect on May 8, 2019 (69; https://www.worldathletics.org/about-iaaf/ documents/health-science). The new regulations apply only to female athletes with XY DSD, having testosterone levels in the male range and normal androgen receptors, and who compete in middle-distance track disciplines at international competitions. Their testosterone levels must be maintained $<5 \mathrm{nmol} / \mathrm{L}$, as measured by gas/liquid chromatography tandem mass spectrometry, to be eligible to compete in the female classification. However, no athlete can be forced to undergo assessment and treatment in response to these regulations. It is solely the athlete's decision, in consultation with her medical team, whether or not to proceed with any evaluation or treatment.

The current clinical consensus is that women with severe hyperandrogenism should be diagnosed and treated in a manner appropriate to their gender identity (31). In the case of female identity, treatment may include suppression of serum testosterone levels by surgical or medical means, as well as gonadectomy if there is a risk of malignancy. In this context, hormonal contraceptives suppress levels of gonadal androgens very effectively also in women with severe hyperandrogenism and are generally well tolerated,

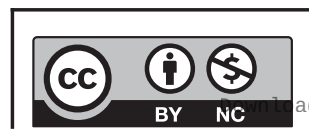


with few side-effects and well-recognized risks, including venous thrombosis (70). However, an athlete may be concerned that such treatment could have an adverse impact on physical performance, and even without treatment she can compete in all events at national level and in any discipline except middle-distance track events at international competitions. At the same time, if untreated, the athlete must be informed of the progressive masculinization of her body, including certain irreversible changes (clitoromegaly, developing deep male voice).

In February of 2019, when the regulations were challenged by another athlete, CAS came to the conclusion that the regulations are necessary, reasonable and proportionate in order to preserve the integrity of female athletes in the restricted events and to ensure fair competition. This decision was appealed to the Swiss Federal Tribunal, which dismissed the athlete's case on July 31, 2019, so that, for the time being, at least these regulations apply to all female athletes. However, at the present point in time, the final decision on the appeal has not yet been taken by the Swiss Federal Supreme Court.

\section{Conclusions}

The present narrative review highlights the complex issue of severe hyperandrogenism in female athletes, including whether it is fair to allow women with male levels of testosterone to compete against those with normal female levels. Findings to date indicate an elevated prevalence of both mild and severe forms of hyperandrogenism among female athletes. This is probably due to selection bias, since essential hyperandrogenism may be advantageous for athletic performance and there is no evidence that athletic activities promote the development of hyperandrogenism. Indeed, increasing scientific evidence indicates that testosterone (exogenous, as well as endogenous) enhances muscle mass and physical performance of women. Furthermore, no known genetic or biological trait provides a better explanation than levels of testosterone for the 10-20\% advantage that male athletes have over female athletes. Nonetheless, whether or not women with high levels of testosterone should be allowed to compete with women with normal female levels remain highly controversial. The regulations established in this context by the IAAF have been approved by CAS, but the final decision by the Swiss Federal Supreme Court is still pending.

\section{Declaration of interest}

A L Hirschberg is a medical and scientific consultant to the Swedish Olympic Committee and a member of the working groups on hyperandrogenic female and transgender athletes set up by the International Association of Athletics Federation (IAAF) and the International Olympic Committee (IOC).

\section{Funding}

A L Hirschberg's research discussed here was financed by grants from the International Athletics Foundation, the Swedish Research Council (2017-02051), the Swedish Research Council for Sport Science and the Karolinska Institutet. Lawley Pharmaceuticals provided the treatment with testosterone and placebo.

\section{References}

1 Nattiv A, Loucks AB, Manore MM, Sanborn CF, Sundgot-Borgen J, Warren MP \& American College of Sports Medicine. Americans College of Sports Medicine position stand. The female athlete triad. Medicine and Science in Sports and Exercise 200739 1867-1882. (https://doi.org/10.1249/mss.0b013e318149f111)

2 Loucks AB \& Horvath SM. Athletic amenorrhea: a review. Medicine and Science in Sports and Exercise 198517 56-72. (https://doi. org/10.1249/00005768-198502000-00010)

3 Loucks AB, Mortola JF, Girton L \& Yen SS. Alterations in the hypothalamic-pituitary-ovarian and the hypothalamic-pituitaryadrenal axes in athletic women. Journal of Clinical Endocrinology and Metabolism 198968 402-411. (https://doi.org/10.1210/jcem-68-2402)

4 Hirschberg AL. Sport and menses. In Encyclopedia of Endocrine Diseases, 2nd ed. vol. 2, pp. 461-470. Eds I Huhtaniemi \& L Martini. Oxford, UK: Academic Press, 2019. (https://doi.org/10.1016/c2016-101662-0)

5 Lindholm C, Hirschberg AL, Carlström K \& von Schoultz B. Altered adrenal steroid metabolism behind hypercortisolism in female endurance athletes? Fertility and Sterility 199563 1190-1194. (https:// doi.org/10.1016/S0015-0282(16)57595-5)

6 Barbarino A, De Marinis L, Tofani A, Della Casa S, D'Amico C, Mancini A, Corsello SM, Sciuto R \& Barini A. Corticotropin-releasing hormone inhibition of gonadotropin release and the effect of opioid blockade. Journal of Clinical Endocrinology and Metabolism 198968 523-528. (https://doi.org/10.1210/jcem-68-3-523)

7 Laughlin GA \& Yen SS. Nutritional and endocrine-metabolic aberrations in amenorrheic athletes. Journal of Clinical Endocrinology and Metabolism 199681 4301-4309. (https://doi.org/10.1210/ jcem.81.12.8954031)

8 Rickenlund A, Thorén M, Nybacka A, Frystyk J \& Hirschberg AL. Effects of oral contraceptives on diurnal profiles of insulin, insulin-like growth factor binding protein-1, growth hormone and cortisol in endurance athletes with menstrual disturbances. Human Reproduction 201025 85-93. (https://doi.org/10.1093/humrep/ dep350)

9 Laughlin GA \& Yen SS. Hypoleptinemia in women athletes: absence of a diurnal rhythm with amenorrhea. Journal of Clinical Endocrinology and Metabolism 199782 318-321. (https://doi. org/10.1210/jcem.82.1.3840)

10 Loucks AB, Laughlin GA, Mortola JF, Girton L, Nelson JC \& Yen SS. Hypothalamic-pituitary-thyroidal function in eumenorrheic and amenorrheic athletes. Journal of Clinical Endocrinology and Metabolism 199275 514-518. (https://doi.org/10.1210/jcem.75.2.1639953)

11 Loucks AB, Verdun M \& Heath EM. Low energy availability, not stress of exercise, alters LH pulsatility in exercising women. Journal of Applied Physiology 199884 37-46. (https://doi.org/10.1152/ jappl.1998.84.1.37)

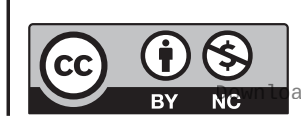

This work is licensed under a Creative Commons Attribution-NonCommercial 4.0 International License. ded from Bioscientifica com at 04/26/2023 12:13:17PM 
12 Loucks AB \& Thuma JR. Luteinizing hormone pulsatility is disrupted at a threshold of energy availability in regularly menstruating women. Journal of Clinical Endocrinology and Metabolism $2003 \mathbf{8 8}$ 297-311. (https://doi.org/10.1210/jc.2002-020369)

13 Melin AK, Heikura IA, Tenforde A \& Mountjoy M. Energy availability in athletics: health, performance, and physique. International Journal of Sport Nutrition and Exercise Metabolism 201929 152-164. (https:// doi.org/10.1123/ijsnem.2018-0201)

14 Hagmar M, Hirschberg AL, Berglund L \& Berglund B. Special attention to the weight control strategies employed by Olympic athletes striving for leanness is required. Clinical Journal of Sport Medicine 200818 5-9. (https://doi.org/10.1097/ JSM.0b013e31804c77bd)

15 Sundgot-Borgen J \& Torstveit MK. Aspects of disordered eating continuum in elite highintensity sports. Scandinavian Journal of Medicine and Science in Sports 201020 (Supplement 2) 112-121. (https://doi.org/10.1111/j.1600-0838.2010.01190.x)

16 Warren MP. The effects of exercise on pubertal progression and reproductive function in girls. Journal of Clinical Endocrinology and Metabolism 198051 1150-1157. (https://doi.org/10.1210/jcem-51-51150)

17 Drinkwater BL, Nilson K, Chesnut CH, Bremner WJ, Shainholtz S \& Southworth MB. Bone mineral content of amenorrheic and eumenorrheic athletes. New England Journal of Medicine $1984 \mathbf{3 1 1}$ 277-281. (https://doi.org/10.1056/NEJM198408023110501)

18 De Souza MJ, West SL, Jamal SA, Hawker GA, Gundberg CM \& Williams NI. The presence of both an energy deficiency and estrogen deficiency exacerbate alterations of bone metabolism in exercising women. Bone 200843 140-148. (https://doi.org/10.1016/j. bone.2008.03.013)

19 De Souza MJ, Nattiv A, Joy E, Misra M, Williams NI, Mallinson RJ, Gibbs JC, Olmsted M, Goolsby M, Matheson G, et al. 2014 Female Athlete Triad Coalition consensus statement on treatment and return to play of the female athlete triad: 1st International Conference in San Francisco, CA, May 2012, and 2nd International Conference in Indianapolis, IN, May 2013. Clinical Journal of Sport Medicine 201424 96-119. (https://doi.org/10.1097/JSM.0000000000000085)

20 Misra M, Katzman D, Miller KK, Mendes N, Snelgrove D, Russell M, Goldstein MA, Ebrahimi S, Clauss L, Weigel T, et al. Physiological estrogen replacement increases bone density in adolescent girls with anorexia nervosa. Journal of Bone and Mineral Research 201126 2430-2438. (https://doi.org/10.1002/jbmr.447)

21 Rickenlund A, Carlström K, Ekblom B, Brismar TB, von Schoultz B \& Hirschberg AL. Hyperandrogenicity is an alternative mechanism underlying oligomenorrhea and amenorrhea in female athletes and may improve physical performance. Fertility and Sterility $2003 \mathbf{7 9}$ 947-955. (https://doi.org/10.1016/s0015-0282(02)04850-1)

22 Rickenlund A, Thorén M, Carlström K, von Schoultz B \& Hirschberg AL. Diurnal profiles of testosterone and pituitary hormones suggest different mechanisms for menstrual disturbances in endurance athletes. Journal of Clinical Endocrinology and Metabolism 200489 702-707. (https://doi.org/10.1210/jc.2003-030306)

23 Hagmar M, Berglund B, Brismar K \& Hirschberg AL. Hyperandrogenism may explain reproductive dysfunction in female Olympic athletes. Medicine and Science in Sports and Exercise 200941 1241-1248. (https://doi.org/10.1249/MSS.0b013e318195a21a)

24 Rosenfield RL \& Ehrmann DA. The pathogenesis of polycystic ovary syndrome (PCOS): the hypothesis of PCOS as functional ovarian hyperandrogenism revisited. Endocrine Reviews 201637 467-520. (https://doi.org/10.1210/er.2015-1104)

25 Teede HJ, Misso ML, Costello MF, Dokras A, Laven J, Moran L, Piltonen T, Norman RJ \& International PCOS Network. Recommendationsfrom the international evidence-based guideline for the assessment and management ofpolycystic ovary syndrome. Fertility and Sterility 2018110 364-379. (https://doi.org/10.1016/j. fertnstert.2018.05.004)
26 Dadgostar H, Razi M, Aleyasin A, Alenabi T \& Dahaghin S. The relation between athletic sports and prevalence of amenorrhea and oligomenorrhea in Iranian female athletes. Sports Medicine, Arthroscopy, Rehabilitation, Therapy and Technology 20091 16. (https:// doi.org/10.1186/1758-2555-1-16)

27 Eliakim A, Marom N, Galitskaya L \& Nemet D. Hyperandrogenism among elite adolescent female athletes. Journal of Pediatric Endocrinology and Metabolism 201023 755-758. (https://doi. org/10.1515/jpem.2010.124)

28 Coste O, Paris F, Galtier F, Letois F, Maïmoun L \& Sultan C. Polycystic ovary-like syndrome in adolescent competitive swimmers. Fertility and Sterility 201196 1037-1042. (https://doi.org/10.1016/j. fertnstert.2011.07.006)

29 Javed A, Kashyap R \& Lteif AN. Hyperandrogenism in female athletes with functional hypothalamic amenorrhea: a distinct phenotype. International Journal of Women's Health 20157 103-111. (https://doi. org/10.2147/IJWH.S73011)

30 Handelsman DJ, Hirschberg AL \& Bermon S. Circulating testosterone as the hormonal basis of sex differences in athletic performance. Endocrine Reviews 201839 803-829. (https://doi.org/10.1210/er.2018-00020)

31 Lee PA, Nordenström A, Houk CP, Ahmed SF, Auchus R, Baratz A, Baratz Dalke K, Liao LM, Lin-Su K, Looijenga 3rd LH, et al. Global disorders of sex development update since 2006: perceptions, approach and care. Hormone Research in Paediatrics 201685 158-180. (https://doi.org/10.1159/000442975)

32 Bermon S, Garnier PY, Hirschberg AL, Robinson N, Giraud S, Nicoli R, Baume N, Saugy M, Fénichel P, Bruce SJ, et al. Serum androgen levels in elite female athletes. Journal of Clinical Endocrinology and Metabolism 201499 4328-4335. (https://doi. org/10.1210/jc.2014-1391)

33 Croson R \& Gneezy U. Gender differences in preferences. Journal of Economic Literature 200947 448-474. (https://doi.org/10.1257/ jel.47.2.448)

34 Hirschberg AL. The role of androgens for body composition and physical performance in women. In Menstrual Cycle Related Disorders, ch 4, pp. 43-54. Eds SL Berga, AR Genazzani, F Naftolin \& F Petraglia. Berlin, Germany: ISGE, Springer Nature, 2019. (https://doi. org/10.1007/978-3-030-14358-9_4)

35 Longcope C. Adrenal and gonadal androgen secretion in normal females. Clinics in Endocrinology and Metabolism 198615 213-228. (https://doi.org/10.1016/s0300-595x(86)80021-4)

36 Burger HG. Androgen production in women. Fertility and Sterility 200277 (Supplement 4) S3-S5. (https://doi.org/10.1016/s00150282(02)02985-0)

37 Labrie F, Martel C, Belanger A \& Pelletier G. Androgens in women are essentially made from DHEA in each peripheral tissue according to intracrinology. Journal of Steroid Biochemistry and Molecular Biology 2017 168 9-18. (https://doi.org/10.1016/j.jsbmb.2016.12.007)

38 Dunn JF, Nisula BC \& Rodbard D. Transport of steroid hormones: binding of 21 endogenous steroids to both testosterone-binding globulin and corticosteroid-binding globulin in human plasma. Journal of Clinical Endocrinology and Metabolism 1981 53 58-68. (https://doi.org/10.1210/jcem-53-1-58)

39 Pretorius E, Arlt W \& Storbeck KH. A new dawn for androgens: novel lessons from 11-oxygenated C19 steroids. Molecular and Cellular Endocrinology 2017441 76-85. (https://doi.org/10.1016/j. mce.2016.08.014)

40 Mooradian AD, Morley JE \& Korenman SG. Biological actions of androgens. Endocrine Reviews 19878 1-28. (https://doi.org/10.1210/ edrv-8-1-1

41 Notelovitz M. Androgen effects on bone and muscle. Fertility and Sterility 200277 (Supplement 4) S34-S41. (https://doi.org/10.1016/ s0015-0282(02)02968-0)

42 Herbst KL \& Bhasin S. Testosterone action on skeletal muscle. Current Opinion in Clinical Nutrition and Metabolic Care 20047 271-277. (https://doi.org/10.1097/00075197-200405000-00006)

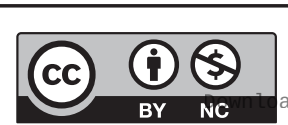

This work is licensed under a Creative Commons Attribution-NonCommercial 4.0 International License. ded from Bioscientifica.com at 04/26/2023 12:13:17PM 
43 Manttari S, Anttila K \& Jarvilehto M. Testosterone stimulates myoglobin expression in different muscles of the mouse. Journal of Comparative Physiology: B, Biochemical, Systemic, and Environmental Physiology 2008178 899-907. (https://doi.org/10.1007/s00360-0080280-x)

44 Almeida M, Laurent MR, Dubois V, Claessens F, O'Brien CA, Bouillon R, Vanderschueren D \& Manolagas SC. Estrogens and androgens in skeletal physiology and pathophysiology. Physiological Reviews 201797 135-187. (https://doi.org/10.1152/ physrev.00033.2015)

45 Shahani S, Braga-Basaria M, Maggio M \& Basaria S. Androgens and erythropoiesis: past and present. Journal of Endocrinological Investigation 200932 704-716. (https://doi.org/10.1007/ BF03345745)

46 Bachman E, Travison TG, Basaria S, Davda MN, Guo W, Li M, Connor Westfall J, Bae H, Gordeuk V \& Bhasin S. Testosterone induces erythrocytosis via increased erythropoietin and suppressed hepcidin: evidence for a new erythropoietin/hemoglobin set point. Journals of Gerontology: Series A, Biological Sciences and Medical Sciences 201469 725-735. (https://doi.org/10.1093/gerona/glt154)

47 Ekblom B, Goldbarg AN \& Gullbring B. Response to exercise after blood loss and reinfusion. Journal of Applied Physiology 197233 175-180. (https://doi.org/10.1152/jappl.1972.33.2.175)

48 Archer J. Testosterone and human aggression: an evaluation of the challenge hypothesis. Neuroscience and Biobehavioral Reviews $2006 \mathbf{3 0}$ 319-345. (https://doi.org/10.1016/j.neubiorev.2004.12.007)

49 Wood RI \& Stanton SJ. Testosterone and sport: current perspectives. Hormones and Behavior 201261 147-155. (https://doi.org/10.1016/j. yhbeh.2011.09.010)

50 Blanco C, Ibanez A, Blanco-Jerez CR, Baca-Garcia E \& Saiz-Ruiz J. Plasma testosterone and pathological gambling. Psychiatry Research 2001105 117-121. (https://doi.org/10.1016/s0165-1781(01)00333-x)

51 Aleman A, Bronk E, Kessels RPC, Koppeschaar HPF \& van Honk J. A single administration of testosterone improves visuospatial ability in young women. Psychoneuroendocrinology 200429 612-617. (https:// doi.org/10.1016/S0306-4530(03)00089-1)

52 Moffat SD \& Hampson E. A curvilinear relationship between testosterone and spatial cognition in humans: possible influence of hand preference. Psychoneuroendocrinology 199621 323-337. (https:// doi.org/10.1016/0306-4530(95)00051-8)

53 Franke WW \& Berendonk B. Hormonal doping and androgenization of athletes: a secret program of the German Democratic Republic Government. Clinical Chemistry 199743 1262-1279. (https://doi. org/10.1093/clinchem/43.7.1262)

54 Huang G, Basaria S, Travison TG, Ho MH, Davda M, Mazer NA Miciek R, Knapp PE, Zhang A, Collins L, et al. Testosterone doseresponse relationships in hysterectomized women with or without oophorectomy: effects on sexual function, body composition, muscle performance and physical function in a randomized trial. Menopause 201421 612-623. (https://doi.org/10.1097/ GME.0000000000000093)

55 Hirschberg AL, Elings Knutsson J, Helge T, Godhe M, Ekblom M, Bermon S \& Ekblom B. Effects of moderately increased testosterone concentration on physical performance in young women: a double blind, randomised, placebo controlled study. British Journal of Sports Medicine 2019 [epub]. (https://doi.org/10.1136/bjsports-2018-100525)

56 Bosco C, Tihanyi J \& Viru A. Relationships between field fitness test and basal serum testosterone and cortisol levels in soccer players. Clinical Physiology 199616 317-322. (https://doi.org/10.1111/j.1475097x.1996.tb00577.x)
57 Cardinale $\mathrm{M} \&$ Stone $\mathrm{MH}$. Is testosterone influencing explosive performance? Journal of Strength and Conditioning Research 200620 103-107. (https://doi.org/10.1519/R-16864.1)

58 Bermon S \& Garnier PY. Serum androgen levels and their relation to performance in track and field: mass spectrometry results from 2127 observations in male and female elite athletes. British Journal of Sports Medicine 201751 1309-1314. (https://doi.org/10.1136/ bjsports-2017-097792)

59 Bermon S, Hirschberg AL, Kowalski J \& Eklund E. Serum androgen levels are positively correlated with athletic performance and competition results in elite female athletes. British Journal of Sports Medicine 201852 1531-1532. (https://doi.org/10.1136/ bjsports-2018-099700)

60 Eklund E, Berglund B, Labrie F, Carlström K, Ekström L \& Hirschberg AL. Serum androgen profile and physcial performance in women Olympic athletes. British Journal of Sports Medicine 201751 1301-1308. (https://doi.org/10.1136/bjsports-2017-097582)

61 Kogure GS, Silva RC, Picchi Ramos FK, Miranda-Furtado CL, Lara LA, Ferriani RA \& Dos Reis RM. Women with polycystic ovary syndrome have greater muscle strength irrespective of body composition. Gynecological Endocrinology 201531 237-242. (https://doi.org/10.310 9/09513590.2014.982083)

62 Bermon S. Androgens and athletic performance of elite female athletes. Current Opinion in Endocrinology, Diabetes, and Obesity 2017 24 246-251. (https://doi.org/10.1097/MED.0000000000000335)

63 Karkazis K, Jordan-Young R, Davis G \& Camporesi S. Out of bounds? A critique of the new policies on hyperandrogenism in elite female athletes. American Journal of Bioethics 201212 3-16. (https://doi.org/ $10.1080 / 15265161.2012 .680533)$

64 Bermon S, Ritzén M, Hirschberg AL \& Murray TH. Are the new policies on hyperandrogenism in elite female athletes really out of bounds? Response to 'out of bounds? A critique of the new policies on hyperandrogenism in elite female athletes'. American Journal of Bioethics 201313 63-65. (https://doi.org/10.1080/15265161.2013.776129)

65 Healy ML, Gibney J, Pentecost C, Wheeler MJ \& Sonksen PH. Endocrine profiles in 693 elite athletes in the postcompetition setting. Clinical Endocrinology 201481 294-305. (https://doi. org/10.1111/cen.12445)

66 Ritzén M, Ljungqvist A, Budgett R, Garnier PY, Bermon S, Hirschberg AL, Vilain E \& Martínez-Patiño MJ. The regulations about eligibility for women with hyperandrogenism to compete in women's category are well founded. A rebuttal to the conclusions by Healy, et al. Clinical Endocrinology 201582 307-308. (https://doi. org/10.1111/cen.12531)

67 Sonksen P, Ferguson-Smith MA, Bavington LD, Holt RI, Cowan DA, Catlin DH, Kidd B, Davis G, Davis P, Edwards L, et al. Medical and ethical concerns regarding women with hyperandrogenism and elite sport. Journal of Clinical Endocrinology and Metabolism $2015 \mathbf{1 0 0}$ 825-827. (https://doi.org/10.1210/jc.2014-3206)

68 Allen DB. Hormonal eligibility criteria for 'includes females' competition: a practical but problematic solution. Hormone Research in Paediatrics 201685 278-282. (https://doi.org/10.1159/000444054)

69 Hirschberg AL. Hyperandrogenism in female athletes. Journal of Clinical Endocrinology and Metabolism 2019104 503-505. (https://doi. org/10.1210/jc.2018-01676)

70 Stegeman BH, de Bastos M, Rosendaal FR, van Hylckama Vlieg A, Helmerhorst FM, Stijnen T \& Dekkers OM. Different combined oral contraceptives and the risk of venous thrombosis: systematic review and network meta-analysis. BMI 2013347 f5298. (https://doi. org/10.1136/bmj.f5298)

Received in final form 28 January 2020

Accepted 20 March 2020

Accepted Manuscript published online 20 March 2020 https://ec.bioscientifica.com https://doi.org/10.1530/EC-19-0537 (c) 2020 The authors Published by Bioscientifica Ltd

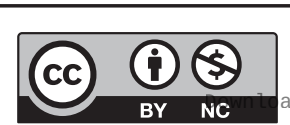

This work is licensed under a Creative Commons Attribution-NonCommercial 4.0 International License. ded from Bioscientifica.com at 04/26/2023 12:13:17PM 